\title{
ESTIMATING THE POLLUTION RISK OF CATCHMENT BASIN IN RIVERS WITH THE FUZZY LOGIC THEORY
}

\author{
Elnaz Khademi ${ }^{1}$ \\ Ramin Asadpour Amazajardi ${ }^{2}$
}

\begin{abstract}
One of the most important problems associated with water is the pollution of surface and underground waters mainly due to human activities that currently threatens many of the world's water resources. The study area of Sabalan dam basin is on Gharasu located at $30 \mathrm{~km}$ (air gap) in Northeast of Meshkinshahr (Ardebil province) on the northern slopes of Mount Sabalan. This study was conducted to identify, classify and manage the pollution risk of Sabalan dam. The overall objective of this study was to predict possible events and identify risk factors, potentials and risks in pollution incidents at Sabalan Dam using URSM methods and fuzzy logic in MATLAB, Fuzzycell and Arc Gis software environments. The results of the URSM method showed that the catchment basin has a pollution risk of 0.43-0.66. The results of this method and fuzzification in the MATLAB software
\end{abstract} revealed that the basin has the risk in the range of 0.16 to 0.76 . Therefore, it can be concluded that using the URSM method and its integration with fuzzy logic in risk assessment can reduce the disadvantages of other methods such as ursm (alone).

Keywords: Risk analysis, Catchment basin, Fuzzy logic, URSM model

\section{Introduction}

One of the most important issues related to water is the surface and groundwater pollution that is mainly due to human activities, which currently threatens many of the world's water resources (Strategic Planning and Control Office of the Presidency, 63: 2009). The occurrence of natural disasters such as flood and earthquakes, accidental and deliberate emission of

\footnotetext{
${ }^{1}$ Department of Industrial Engineering, Shiraz Branch, Islamic Azad University, Shiraz, Iran.*Corresponding Author Email: khademielnaz72@gmail.com.

${ }^{2}$ Department of Industrial Engineering, Shiraz Branch, Islamic Azad University, Shiraz, Iran.Email: asadpour.ramin93@gmail.com.
} 
pollutants into water resources and other incidents such as accidents in installations, transportation and transfer of hazardous materials that have harmful effects on the environment are among the most important issues affecting many societies. The increasing rate of such events over the past few decades has led many societies, especially Western societies, to take extensive measures to prevent the recurrence and exacerbation of these cases (Simeonov et al., 2003: 4). Establishing laws and regulations, increasing safety in water distribution systems, developing standards, increasing the penalty for pollution of water resources and ... are among the measures that have been implemented in many countries over the past years (Ho, KC \& et al 2003: 3). A large part of the country's regions face limited water resources and the incorrect use of the limited water resources and pollution in these resources will lead to environmental crises and disasters (Nazari Dost, 3: 2009). The growing trend of the country's development, the expansion of industrial centers, the excessive use of pesticides and fertilizers in agriculture, the discharge of wastewater into receiving water resources, agricultural drainage and home and hospital sewage severely threaten the quantity and quality of the country's limited and valuable water resources. The growing demand in the community for access to water resources of appropriate quality, the significant increase in new water supply costs and the need to control the pollution of water resources with respect to the country's water scarcity have cause the water resources management face serious challenges in many aspects (Ministry of Energy, 54: 2009). Environmental risk assessment is a step beyond the risk assessment and in addition to examining and analyzing various aspects of risk, while the full recognition of the environment in the affected area, the sensitivity of the affected environment, as well as the specific environmental values of the area are considered in the risk analysis of the region (Heller,s \& et al., 2006: 4). Lack of enough attention to the severe influence of water quantity on its quality and the marginalization of water quality management in most comprehensive water resources studies has caused many environmental problems along the river paths and their downstream areas. Since Iran is in a dry and semi-arid region, the necessity of qualitative studies of water resources and 
considering this issue in the form of imposing legal constraints for quality management of each of the rivers of the country is of special importance (Ministry of Energy 11: 2013). As the conducted studies in the scope of this study have often been used to monitor the quality of water and a comprehensive study has not been carried out to calculate the risk, the URSM method is used to assess the risk of water pollution in the Sabalan dam with respect to the available facilities and conditions.

Risk management science was introduced in the Renaissance in the sixteenth century. Since 1990, various models have been proposed for project risk management with the aim of increasing their success (Boehm, 1991; Cooper et al., 2005: 7,9). Amini Rad and Ghafari (2008) in a research on the evaluation of pollutants in Caspian Sea environment in Mazandaran province, determined evaluated their the risk of the pollutants, evaluated their relative risk and provided the ground for determining the planning priorities for controlling pollutants by identifying pollutant sources through the comprehensive system of pollutant rating (Amini Rad and Ghafari, 2008). Mohammadpour and Khoshvaran (2006) in a study entitled
"Haraz River risk source assessment using the creation and data exchange between ArcView GIS software and the MS Excel computing environment" implemented the URSM model on the data and identified and ranked pollution sources in terms of environmental hazard and assessed the risk posed by them. By combining the results of risk assessment and adaptation with reported data from the monitoring, a comprehensive assessment of the pollution sources of the Haraz River has been obtained and a suitable field is provided for determining the priorities for controlling the pollutants (Mohammadpour and Khoshvaran, 2006: 7).

Moghaddam, (2010), in a study on zoning the degree of risk and environmental vulnerability of the International Miankaleh Wetland using the GIS, assessed the sources of pollutants around the lagoon and planed the comprehensive risk assessment system. The study of the obtained maps showed that according to the distribution of industrial units, the severity of vulnerability in the central, northeastern, and western parts of the wetland is more than other areas (Moghaddam, 2010: 9).

The selected site of the catchment area of Gharasu is located at 
$30 \mathrm{~km} \mathrm{(air} \mathrm{gap)} \mathrm{in} \mathrm{Northeast} \mathrm{of}$ Meshkinshahr (Ardebil province) on the northern slopes of Mount Sabalan. The coordinates of the intersection of the river with the dam axis are $38^{\circ}-32^{\prime}$ and $47^{\circ}-58^{\prime}$. The area of this basin is 2131 sq. $\mathrm{Km}$, the average height is $1601 \mathrm{~m}$, the average slope of the basin is $10.2 \%$ and the main river length is $58 \mathrm{~km}$.

\section{Materials and Methods}

In this research, URSM methods have been used to assess the risk of pollution in the Sabalan dam catchment. ARC GIS has been used to determine the study area and sub-basins. The stages of the research are summarized as follows:

- Collection of information and review of study records

- Identification of factors affecting the river based on available information and visiting the area including:

- Preparing the distribution of activities in the GIS environment

- Recording the characteristics of influencing activities in the database including: public information, index pollutions and their amount, receiving source of pollution and the coordinates of the discharge location

- Analyzing the data and information using these indices

- Writing membership functions in the MATLAB software environment and providing vulnerability mapping in the fuzzycell software environment

\subsection{Methods of data collection:}

1- Based on field studies and especially pollution potentials, and using hydrologic patterns of the basin, each dam is divided into several study regions and risk assessment is performed at the level of regions.

- Field operations and taking notes

- Using valid and practical resources

- Plans and studies conducted in the basin

- Interpreting satellite images

\section{Research Method}

The researchers referred to the universities and research institutes and using the available research reports, the data needed for research were prepared and extracted. The set of obtained 
information is processed in the computer environment. Data processing includes preparation of data in the computer environment to be interpreted, analyzed, and updated. The data was categorized as tables in processing.

\subsection{Creating a comprehensive rating} model for the risk of pollution sources

In order to meet the needs of this research, sources of pollutant data were first collected. The following properties were identified essential for the data of this study:

Data validity (suitable and appropriate data)

Data validation
452

In the initial definition, the fuzzy sets as the basis of the comprehensive rating system for pollution sources is the membership function of a set of a fixed function whose range is a non-zero real number with a maximum value, which is normally equal to one. This type of set is called the fuzzy set of the first type. Now the second type of fuzzy set is defined. Definition: the second type fuzzy set is a set that its membership function is the type 1 fuzzy set.

For example: if the reference set is $X=\{1,2,3, \ldots, 10\}$

The second-type fuzzy set A is given as $\mathbf{A}=\{(\mathbf{x}, \boldsymbol{\mu} \mathbf{A} \sim(\mathbf{x}))\}$ is considered for $\mathrm{x}=3$ with the following membership function:

$$
\mu_{\mathrm{A}^{\sim}} \sim(3)=\left\{\left(\mu \mathrm{i}, \mu_{\mu \mathrm{i}}(3)\right) \mid \mathrm{i}=1, \ldots, 3\right\}(1)=\{(0 / 8,1),(0 / 7,0 / 5),(0 / 6,0 / 4)\}
$$

Similarly, fuzzy sets of type 3 and higher can be defined.

To create this model, the sources of pollutants were first categorized into specific categories, so that each category contains a variety of resources that have similar characteristics. Then, the criteria for each of these categories of resources are identified as a source with the risk of pollutant production (Fig. 1). The defined criteria for each category are the parameters in Table (1), with the difference that for each type of pollution, the parameters of the same pollution have been analyzed and given the large number of parameters, only one sample that is related to pollutants of industrial origin is described for better understanding (Table 1). 
In defining these criteria, it is important to note that the criteria provide the need for research information about those sources of pollution. Meanwhile, they should be consistent with the data
453 level available in the data sources of this research. At this stage, it was possible to find a position in each system for each pollutant found within the scope of the research objectives (Fig. 2).

Table1-Classification of sources of pollution and their defined characteristics plus the $\mu$ scores assigned to each one

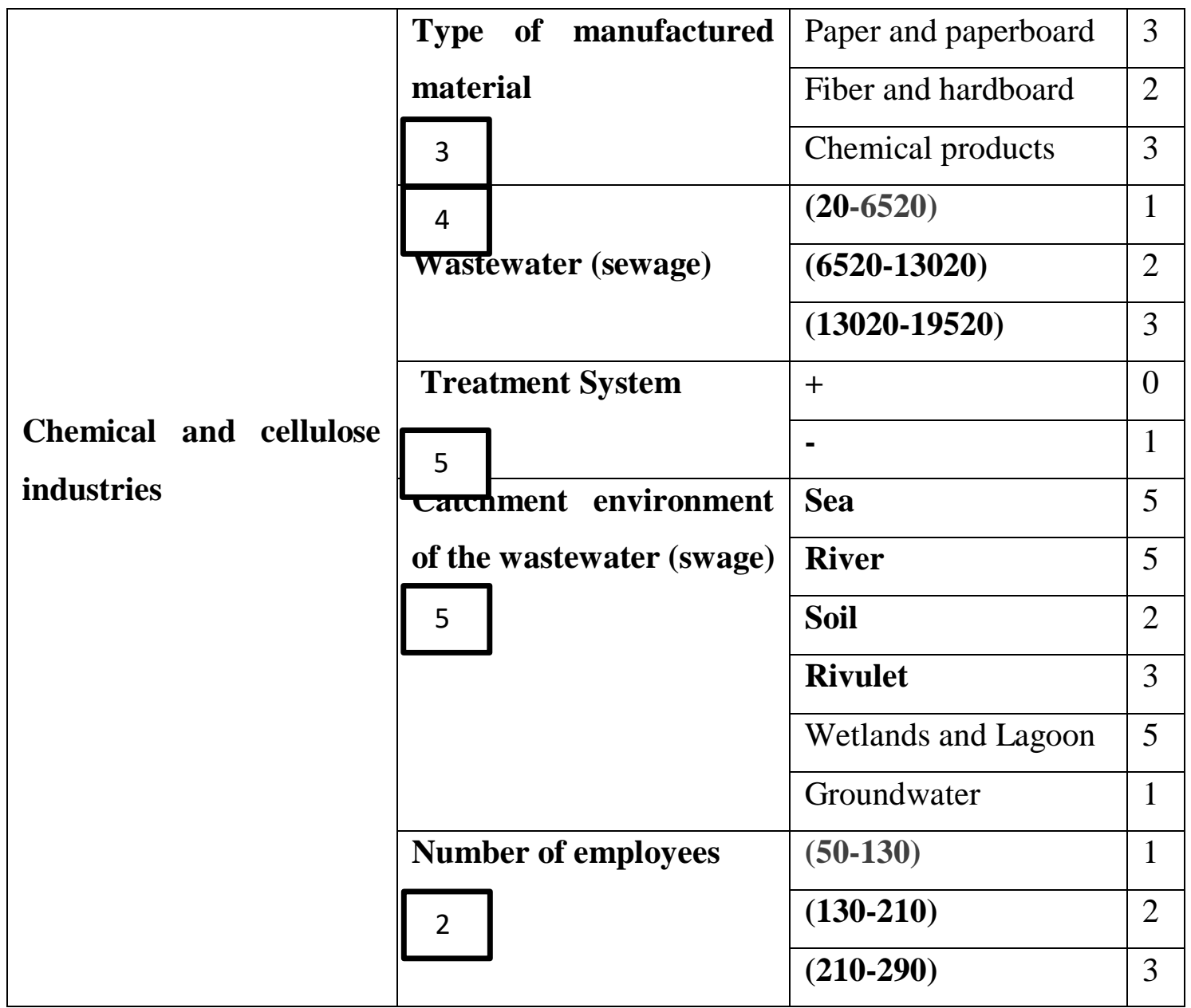

Source: Moghaddam, 2010:45

\subsection{According to the food industry table the scores are calculated as follows:}

The score of manufactured

Amount of wastewater: 1 out of material: 4 out of 5 scores 
Treatment system: 0 out of 2

scores

Wastewater catchment

environment: 2 out of 5 scores

Number of personnel: 1 out of 3

By dividing $\mu$ of the members, i.e., the weight of the set and multiplying each by the second type fuzzy set, the risk rate the industrial slaughterhouse in Ardabil is obtained:

scores

$$
\operatorname{RISK}=\left(\frac{4}{5} \times \frac{3}{5}\right)+\left(\frac{1}{3} \times \frac{5}{5}\right)+\left(\frac{0}{2} \times \frac{5}{5}\right)+\left(\frac{2}{5} \times \frac{5}{5}\right)+\left(\frac{1}{3} \times \frac{5}{5}\right)=1.547
$$

To normalize these numbers, once again, this set is divided by 3 (the weight of the second type fuzzy set), and the resulting risk number for the industrial slaughterhouse in Ardabil will be 0.5156 .

\section{$\frac{1.547}{3}=0.5156$}

In order to implement this model, there was a need for a suitable software environment. Due to the spatial nature of the data, after the review of the various software programs in the GIS field, the ARC GIS software was recognized as suitable for the task. Finally, seven map layers included the agricultural layer of the food industry, the chemical industry layer, the nonmetallic and non-metallic mineral layer around the lagoon and villages in the basin. The fuzzy logic theory was used to compare the rate of pollutant sources. Then the model was implemented on the geographic information bank, which was done with calculating risk rate of different sources of pollutants and exchanging information between the software system and the MS Excel software. In the finalized maps in GIS environment, it became clear which region of the basin has food industry as a source with high pollution potential and which region has chemical industry with high pollution.

\section{Results}

By implementing the URSM system, and calculating the relative degree of risk of each pollutant source, the sources of pollution were compared 
with each other. To compare the rate of pollution sources with respect to their calculated rate, the fuzzy sets theory was used again. The results of the URSM method showed that the catchment area has a pollution risk of $0.43-0.66$. The results of the fuzzy logic method indicate that the basin has the risk in the range of 0.16-0.76. The results suggest that the fuzzy method clearly shows uncertainty in the environmental issues.

In order to determine the areas of the basin with higher environmental risk potential, final maps were prepared in the GIS environment that the results of overlapping of the layer, which contain the total risk of the basin, are presented Discussion

After identifying and classifying pollution sources in the basin and referring to the various types of pollutions associated with them, theoretically, different types of pollutants were assessed in waters and soils of the basin, including rivers, and underground and soil resources based on the existing statistics according to the URSM method. According to the abovementioned content, the highest pollution in the basin with respect to industries was associated with pesticides and agricultural fertilizers. According to the results, Sabalan Dam due to the existence of urban, rural, industrial sources of pollution in its basin, has pollution risks and according to the results of the URSM method, the pollution risk is $0.43-0.66$. Therefore, the use of the URSM method and its integration with fuzzy logic can be useful in assessing the pollution risk of the Sabalan dam basin and reduce the shortcomings of this method.

\section{Conclusion}

Due to the occurrence of natural or man-caused disasters, the use of scientific methods to estimate the pollution risk of dams as one of the important sources of drinking, industry and agricultural water supply is essential. The risk assessment models presented in this study are used to determine the potential for surface water pollution, which is based on the hydrologic indicators of the area and land use. According to the above-mentioned issues, the highest pollution in the basin respect to industries was associated with pesticides and agricultural fertilizers, which is due to the establishment of agricultural and industrial sectors around the city of Ardabil. According to the results, Sabalan Dam due to the 
existence of urban, rural, industrial sources of pollution in its basin, has pollution risks and in this regard, the URSM method is suitable for classifying and prioritizing environmental risks in dams' pollution incidents.

MIKE and WASP methods are among the proposed programs, which are carried out after risk assessment, are models for monitoring the effects of pollution in the dam reservoir, which will have a significant effect on the detection of potential pollution in the dam reservoir.

\section{Refrence}

Amini Rad, Hassan and Ghafari Hafiz. (2008), Assessment of Environmental Pollutants in the Caspian Sea in Mazandaran Province. Second Special Conference and Exhibition on Environmental Engineering. University of Tehran.

Boehm, B.W. (1991). Software risk management: Principles and Practices. IEEE software, 8, 32-41.

Bowles, D.S.2008. portfolio risk assessment: a tool for managing dam safety in the context of the owners business, ICOLD $20^{\text {th }}$ congress.

Cooper, D.F., Grey, S., Raymond, G. and Walker, P. (2005). Project risk management guidelines: Management risk in large projects and complex procurements. Chichester, John Wiley and sons.

East Azarbaijan and Ardebil Regional Water Company, (2005), Environmental Impact Assessment Report of Sabalan Dam, Netpa Consulting Engineers.

Heller,S,2006.Managing Industrial Riskhaving a tasted and proven system to prevent and assess risk. journal of hazardous material130,pp.58-63.

Ho, K.C., Chow, Y.L., Yau, J.T.S. (2003). Chemical and microbiological qualities of The East River Dongiang water, with particular reference to drinking water supply in Hong Kong.chomospHere. 52, 1441-50.

Iranian Environmental Protection Agency, (2011), Guide to Calculating Water Quality Indicators of Iran, Environmental Protection Organization Publications. 
Ministry of Energy, (2010), Vice

President of Strategic Planning and

Supervision, Office of Engineering and

Technical Criteria for Water and Water

Resources, Guide to the Study of Self-

Purification Rivers. Journal No. 481. 151

pages.

Ministry of Energy, (2013), Guidelines

for the Management of Pollution

Disaster Risk in Surface and

Groundwater Resources. Journal 407 - a.

Moghaddam, Mona, (2010), Risk

Mapping and Environmental

Vulnerability of Miankaleh International

Wetland Using GIS Geographic System,

M.Sc., Islamic Azad University, Science

Research Branch.

Mohammadpour, Maryam, and

Khoshravan Homayoun (2010),

Evaluation of Potential Resource

Hazards on the Haraz River, Twenty-

fifth Geological Survey of Iran,

Geological Survey and Mine

Exploration Organization of Iran.

Nazari Doost, Ali, (2009), Risk Management of Dam Contamination Dam Operated by Tehran Regional
Water Company, Report of Asarab Consulting Engineers.

Simeonov, V., Stratis, J. A., Samara, C., Zachariadis, G., Voutsa, D., Anthemidis, A., Sofoniou, M. \& Kouimtzis, Th. (2003), "Assessment of the Surface Water Quality in Northern Greece," Water Research, 37, pp 4119-4124.

Vice President of Strategic Planning and Supervision, (2009), Current Surface Water Quality Guidelines (Issue No. 522 